\title{
LINGUISTIC PROGMATICS OF ENGLISH BORROWINGS IN RUSSIAN MASS COMMUNICATION DISCOURSE
}

\author{
Olga S. Volkova \\ Volgograd State University, Volgograd, Russia
}

\begin{abstract}
The paper focuses on linguistic and pragmatic peculiarities of English borrowings used in the discourse of mass communication in Russian. The analysis of Russian-language web content has enabled the author to identify the symbolic significance of shoe names borrowed from the English language. The system of values referred to a fashionable lifestyle was revealed and described; the thematic domains, such as sports, healthy lifestyle, active life position, and eco-activism are highlighted. The shoe names borrowed from English are regarded in the article in terms of translingual units and are defined as linguistic signs, which belong to another language, but the speakers, who are the agents of network communication, use them ad hoc to convey the ideas through switching the language code. Translingual units are found out to be universal symbols in the context of global mass culture. Having crossed the borders of the languages, they broadcast new values. Meanwhile, they spontaneously go through the main stages of linguistic adaptation and actively penetrate the network content of mass communication. The article presents the techniques of the borrowed shoe names translingual adaptation. The identified techniques include translingual derivation, partial grammatical categorization, conversion and blending, which consists in the occasional composition of the original, graphically unadapted English stem - a proper noun denoting a brand name of the shoe manufacturer, and a Russian suffixoid -ovsk-, which forms relative adjectives with the generalized meaning of sharing characteristics, prescribed to the object, indicated by the root morpheme. Phonetic assimilation of translingual shoe names presupposes following pronunciation rules of the Russian language, including the reduction of vowels in the first pre-stressed syllable; devoicing voiced consonants at the end of a word; palatalization; coexistence of diphthongized and monophthongized variants of vowel pronunciation, which indicates the incompleteness of phonetic adaptation.

Key words: borrowing, translingual unit, mass communication discourse, linguistic adaptation, values of web communication, fashionable lifestyle, shoe names.

Citation. Volkova O.S. Linguistic Progmatics of English Borrowings in Russian Mass Communication Discourse. Vestnik Volgogradskogo gosudarstvennogo universiteta. Seriya 2. Yazykoznanie [Science Journal of Volgograd State University. Linguistics], 2021, vol. 20, no. 6, pp. 134-145. (in Russian). DOI: https://doi.org/ 10.15688/jvolsu2.2021.6.12
\end{abstract}

\section{ЛИНГВОПРАГМАТИКА АНГЛИЙСКИХ ЗАИМСТВОВАНИЙ В РУССКОЯЗЫЧНОМ ДИСКУРСЕ МАССОВОЙ КОММУНИКАЦИИ (НА МАТЕРИАЛЕ НАЗВАНИЙ ОБУВИ)}

\section{Ольга Сергеевна Волкова}

Волгоградский государственный университет, г. Волгоград, Россия

Аннотация. В статье рассматривается проблема лингвопрагматического использования английских заимствований в дискурсе массовой коммуникации на русском языке. На материале русскоязычного сетевого контента (письменного и устного) выявлена символическая значимость заимствованных англоязычных именований обуви, установлена ценностная специфика модного образа жизни и выделены тематические области ее реализации: спорт, здоровый образ жизни, активная жизненная позиция, экоактивизм, 
при описании которых употребляются заимствованные англоязычные именования обуви. Заимствованные номинации обуви определены как транслингвальные единицы - языковые знаки, принадлежащие другому языку, но ситуативно применяемые носителями - агентами сетевой коммуникации для передачи своих идей посредством переключения языкового кода. Транслингвальные единицы представляют собой универсальные символы в контексте глобальной массовой культуры и, пересекая границы языков, транслируют новые ценности. При этом они спонтанно проходят основные этапы лингвистической адаптации и активно включаются в сетевой контент массовой коммуникации на принимающем языке. В статье охарактеризована фонетическая ассимиляция транслингвальных названий обуви, которая отражает свойственную нормам произношения русского языка редукцию гласных в первом предударном слоге, оглушение звонких согласных звуков на конце слова, палатализацию, сосуществование дифтонгизированных и монофтонгизированных вариантов произношения гласных, сигнализирующие о незавершенности фонетической адаптации. Представлены приемы транслингвальной адаптации заимствованных номинаций обуви: транслингвальная деривация, частичная грамматическая категоризация, конверсия и блендинг.

Ключевые слова: заимствование, транслингвальная единица, дискурс массовой коммуникации, лингвистическая адаптация, ценности сетевой коммуникации, модный образ жизни, названия обуви.

Цитирование. Волкова О. С. Лингвопрагматика английских заимствований в русскоязычном дискурсе массовой коммуникации (на материале названий обуви) // Вестник Волгоградского государственного университета. Серия 2, Языкознание. - 2021. - Т. 20, № 6. -C. 134-145. - DOI: https://doi.org/10.15688/jvolsu2.2021.6.12

\section{Введение}

Изучение заимствований иноязычной лексики в отечественной лингвистике опирается на теорию ассимиляции и адаптации чужих слов как иноязычных вкраплений [Реформатский, 1967; Леонтьев, 1966; Князева, 1970]. Мотивация и стадии заимствования в условиях опосредованных и непосредственных языковых контактов детально описаны в работах современных исследователей [Крысин, 1968; 2002; Кимягарова, 1989; Диброва, 2008; Свинцова, 2006]. С начала ХХІ в. лингвисты наблюдают активное проникновение англоязычной лексики в практику массовой коммуникации на русском языке. В своих исследованиях они анализируют специфику адаптации английских слов к словообразовательным и грамматическим нормам русского языка [Дьяков, Скворецкая, 2013; Пономарёва, 2001], семантический аспект освоения англицизмов в разных регистрах речи [Павленко, 1998; Прокутина, 2009]. Обосновывая причины интенсивного заимствования англицизмов в современный русский язык, ученые, наряду с историко-культурным [Крысин, 1968; Дьяков, 2003], выделяют прагматический фактор [Китанина, 2005], полагая, что лингвистическое изучение процесса заимствования следует проводить на коллекциях текстов, принадлежащих к различным сферам коммуникации. Например, опубликованы данные об адаптации англицизмов в экономическом, юридическом, политическом, филологи- ческом дискурсах, в сфере игровой, рекламной индустрии [Горностаев, 2017], однако малоисследованной, но значимой для изучения особенностей транслингвальной адаптации остается тема заимствования англоязычной лексики в современной массовой коммуникации о модном образе жизни, прагматика и стилистика ее употребления в речи.

В данной статье предполагается обоснование гипотезы о транскультурной значимости английских заимствований в русскоязычном дискурсе о модном образе жизни, отраженной в прагматике спонтанного появления новой единицы в тезаурусе русскоязычного агента сетевой коммуникации о модном образе жизни при обсуждении ценностей и символов массовой культуры.

Введение в настоящее исследование понятия транскультурной значимости заимствованной единицы опирается на сформулированные в современной теории коммуникации положения о транслингвизме, или трансъязычии [Canagarajah, 2002; Gardner-Chloros, 2009], как динамичном развитии языков в условиях опосредованных и непосредственных языковых контактов. Обосновывая коммуникативную ценность того или иного заимствования исследователи указывают на особые социокультурные условия, при которых, в связи с ростом количества людей, владеющих одним или несколькими иностранными языками наряду со своим родным, в процессе интеракции они прибегают к употреблению в речи 


\section{МАТЕРИАЛЫ И СООБЩЕНИЯ}

транслингвальных единиц - языковых знаков, принадлежащих другому языку, ситуативно применяемых («ad hoc») для передачи своих идей посредством переключения языкового кода [Kochetova, Ilyinova, 2020]. Транслингвальные единицы, одновременно попадая в несколько языковых сред, приобретают универсальную ценность в контексте глобальной массовой культуры, тем самым демонстрируя транскультурную значимость заимствования.

\section{Материал и методы}

Анализ сетевой коммуникации о модном образе жизни возможен через изучение тезауруса агента сетевой коммуникации о модном образе жизни. Прагматика появления транслингвальных единиц заключается в формировании потребности употребления единиц, необходимости подбора языковых единиц для номинации новых предметов или явлений. Именно такими единицами выступают транслингвальные образования.

Источником для отбора языковых единиц послужили тексты русскоязычных журнальных публикаций, блогов о модном образе жизни, отзывов интернет-магазинов, содержащих заимствованные из английского языка номинации обуви (общее количество - 54 лексические единицы в 154 контекстах). Был проведен лингвопрагматический анализ употребления транслингвальных единиц и особенностей их адаптации, проходящей в условиях спонтанной коммуникации о модном образе жизни в сетевом контенте. Общая методика анализа предполагала сочетание приемов описания словообразовательных процессов адаптации англоязычного заимствования к нормам русского языка, формирования семантики и синтагматики использования в русскоязычном тексте с приемами лингвопрагматической интепретации контектуального употребления.

\section{Результаты и обсуждение}

\section{Языковая адаптация заимствований}

Фонетическое освоение заимствованного слова проявляется в изменении его звукового облика, которое происходит по законам языка-реципиента. Степень адаптации может быть различной. Если в заимствованном слове все звуки соответствуют единицам звукового состава языка-реципиента, то произнесение данного слова у его носителей не вызывает затруднений, однако чуждые языкуреципиенту звуки заменяются наиболее близкими по звучанию. Так, действующие в русском языке фонетические законы, например редукция гласных в первом предударном слоге, когда [о] произносится как [^], распространяются и на транслингвы, которые в процессе фонетической ассимиляции начинают произноситься по аналогии с русскими словами: б[^]тфортыл, м[^]касиныл. Фонетические законы произношения согласных требуют оглушения звонких согласных на конце слова: бро[к] вместо бро[г], кло[к], а не кло[г]; палатализации: $c[л$ ']ипоны, тим[б ']ерленды. По нормам русского языка перед гласным [э] произносится мягкий согласный: [ло́ф ’эры], [cл'un'эры], [конв эр нетической адаптации по данному параметру в ряде случаев еще не завершен: [лабутэны], [mon сайдэдыl], [гриндэрсыl]. Сосуществова-

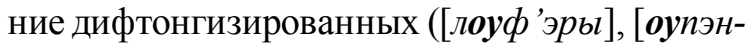
mой]) и монофтонгизированных ([лоф ’эры ], [опэнтой]) вариантов произношения гласных сигнализирует о незавершенности процесса фонетической адаптации некоторых транслингвальных именований обуви.

Под графическим освоением транслингвальных единиц понимается передача на письме перешедшего слова графическими средствами языка-реципиента, в нашем материале - кириллицей (например, slipper - cлиnер). Графическая адаптация транслингвального слова занимает не так много времени, как, например, грамматическая, однако и здесь единое графическое изображение устанавливается не сразу. Было отмечено, что на начальном этапе графической ассимиляции транслингвальных названий обуви в русскоязычных текстах встречаются варианты с графической передачей их первоначального написания, например ankle boots, kitten heel:

(1) Надеваем носки с ankle boots поверх леггинсов (I);

(2) Предпочитающие более комфортную обувь найдут в коллекции аккуратные kitten heels в стиле Одри Хепберн (II). 
Иногда в скобках дается определение иноязычных названий обуви на русском языке. Это делается для уточнения нового, пока неизвестного читателю понятия:

(3) Туфли на низком каблуке (он же kitten heel) самое правильное решение для тех, кто не в состоянии каждый день проявлять бытовой героизм и бегать на высоченных шпильках, но при этом пока не готов окончательно спуститься с небес на землю и отказаться от лодочек в пользу балеток, слиперов и прочих прозаично-удобных вариантов (III).

Неравномерную графическую адаптацию транслингвальных единиц со сходной морфемной структурой наблюдаем при переходе обувных названий docksiders - доксайдеры, Top-Siders - mon-сайдеры / moncaŭдеpbl. Отметим расхождения в слитном и дефисном написании последнего и упразднении прописных букв:

(4) Этим летом о морских круизах будут напоминать не только тельняшки, топ-сайдеры и эспадрильи на джутовой подошве, широкополые шляпы, короткие шорты и ледяное шампанское, но и коллекция декоративной косметики МАC «Неу, Sailor!» (IV).

Полностью графически адаптировавшимися считаются транслинвальные единицы, которые в русском языке передаются на письме буквами русского алфавита. Это доказывает максимальную стадию графической адаптации: derby - дерби, Mary Jane - Мэри Джейн, chelsea - челси:

(5) Однако самой популярной моделью мужской обуви в женском гардеробе этой осенью стали челси, обыгравшие лидирующие прежде по популярности оксфорды разве что не всухую (V).

В случае актуализации нескольких языковых явлений при транслингвальном переходе объект или явление может получить номинацию с отличным от исходного объемом лексического значения, например ореn toe - опентой:

(6) Как всегда, летом будет актуальна обувь опентой. Первейшей из модниц вы сможете прослыть, если прикупите обувь не просто с открытым носочком, но и с пластиковыми вставками (VI).

Заимствованное англоязычное словосочетание (open toe $[\mathrm{adj}+\mathrm{N}]$ ), обозначающее от- крытый палец, транскрибируется и входит в принимающий язык как единая словоформа, графически передаваемая кириллицей без пробелов - опентой (модель обуви с вырезанным мысом).

Грамматическая адаптация представляет процесс подчинения формы транслингвальной единицы законам грамматики русского языка. Заимствованные слова - в нашем материале это парные имена существительные демонстрируют частично или полностью, в зависимости от степени грамматической адаптации, признаки грамматических категорий: род, число, склонение, падеж.

Из 54 отобранных наименований обуви только 18,5 \% заимствований имеют показатели грамматического рода и единственное число: мокасин (муж. род), брог (муж. род), платформа (жен. род), конверс (муж. род), крипер (муж. род), кед (муж. род), лофер (муж. род), оксфорд (муж. род), слипон (муж. род), слипер (муж. род); остальные 81,5 \% только множественное число: челси, кроги, хилисы, слаучи, ридинги, джодпур, мон$\kappa и$, томсы.

Следует отметить, что схожие в английском языке по фонетическому и морфемному составу слова flatform и platform, обозначающие форму подошвы, адаптировавшиеся к нормам русского языка в разные исторические периоды, приобрели разные грамматические характеристики: flatform употребляется только в форме множественного числа и не имеет родовой принадлежности - флатформы, в то время как platform имеет формы единственного и множественного числа, а в единственном числе склоняется по парадигме женского рода: платформа, туфли на платформе. Это объясняется тем, что полисемичное слово платформа давно существует в русском языке с полной парадигмой грамматических показателей.

Подчинение транслингвальных единиц правилам русского языка привычно наделяет обувные лексемы показателем множественного числа, позволяя при этом упростить графическое исполнение, и в русском варианте сложносоставные слова пишутся слитно: winklepicker / винклпикеры (winkle-picker (n) - a shoe or boot with a narrow, sharply pointed toe, popular in the 1950s (COED) - туф- 


\section{МАТЕРИАЛЫ И СООБЩЕНИЯ}

ли или ботинки с узким, заостренным мысом, популярные в 1950-х гг. (здесь и далее перевод с английского наш)); slip-on / слипоньл. В некоторых случаях финальный компонент, номинирующий тип обуви, в процессе перехода опускается: oxford shoes / оксфорды, Birkenstock sandals / биркенштоки. Грамматический показатель множественного числа при употреблении иноязычных названий обуви в русском языке не добавляется к основе с финальным гласным звуком: tabi / maби, Derby shoes / дерби, chelsea boots / челси.

В словосочетаниях, номинирующих обувь на основе метонимического переноса, в русском языке используется семантическое калькирование: cowboy boots / ковбойские canoгu, kitten heels / кошачий каблук. Данный прием позволяет коротко и емко описать модель, сохраняя порядок следования элементов транслингвальной единицы (Dockside boat-shoes / яхтенные туфли) или меняя его, адаптируя к привычному для носителя русского языка порядку: glove shoes / туфли-перчатки, stretch leather ankle boots / полусапоги-носки.

Анализируя процессы адаптации заимствованных названий обуви, мы наблюдаем конверсию - переход слов из одной части речи в другую, в частности переход существительных (имен собственных, номинирующих компаниюпроизводителя обуви) в прилагательные при помощи русского суффикса -вск-/-овск-, образующего относительные имена прилагательные с общим значением свойственности тому или характерности для того, что названо мотивирующим словом. При этом заимствованная корневая морфема графически не всегда ассимилируется. В результате формируется весьма продуктивная деривационная модель с различными вариантами графической репрезентации:

а) дефисное написание корневой и аффиксальной морфем:

(7) Etonic-овских ботинок (VII);

(8) в ЕССО-вских ботинках (VIII);

(9) модели Рuma-вских балеток (IX);

б) написание с апострофом в русской и английской алфавитных раскладках:

(10) Reebok'oвские кроссовки; переместили традиционные adidas'oвские полоски с плеч на боковую сторону формы (X);
(11) ...Исключение составляют Mizuno'вская волна и Nike'овские воздушные подушки (XI);

в) использование кавычек для заимствованной номинации бренда:

(12) На Ямале снова изымают «пиратские» диски и контрафактные «ADIDAS»овские кроссовки (XII).

Слова, образованные от транслингвальных обувных номинаций с помощью конверсии из существительного в глагол, немногочисленны. Восприятие модели $\mathrm{N} \rightarrow \mathrm{V}$ позволяет участникам коммуникации о моде распознать семантику транслингвального деривата, например boots (n) - бyuаmь / бymcamb (v), to bump (v) - bumps (n) - (по)бампкать (v):

(13) В кроссовках этих фирм бегали и буцали мяч только советские футболисты (XIII);

(14) ...И первоначально относилось к обуви для зала, в которой можно «бампкать и буцать» (XIV).

Итак, в процессе употребления транслингвальных названий обуви коммуниканты сетевого дискурса спонтанно уподобляют словоформы к фонографическим и грамматическим нормам русского языка, используя следующие приемы: транслитерация с элементами оглушения финального консонанта, редукция гласных в первом предударном слоге, частичная грамматическая категоризация, конверсия.

\section{Контекстуальная адаптация}

Ценности массовой культуры транслируются через текстовый контент постов в микроблогах, социальных сетях, на онлайн-каналах, посвященных моде и красоте, шопингу, путешествиям, спорту и здоровому образу жизни. Употребление транслингвальных названий обуви в контексте данной тематики имеет характер саморепрезентации автора как человека, сведущего в новинках, последних тенденциях моды и стиля. Иноязычная лексика, спонтанно инкорпорируемая в речь, забавляет и увлекает слушателя или читателя, также владеющего иностранным языком и мастерством переключения кода, а менее продвинутыми в языковом плане адресатами незнакомые, чужие, заимствованные названия 
воспринимаются как маркер просвещенности и информированности адресанта, показатель опыта заграничных поездок, где именно так эти новинки и называются. Регулярность употребления в речи модных блогеров транслингвальных единиц воспринимается массовой аудиторией как маркер достатка - возможности путешествовать за границу, посещать элитные торговые центры и аутлеты, приобретать дизайнерскую обувь.

Массовая культура на современном этапе своего развития отражает ценности, конвенции и представления, сформировавшиеся за последние 5-10 лет и составляющие модный образ жизни. Они воплощены в четких когнитивных установках носителей массовой культуры о публично одобряемых и порицаемых аспектах модного образа жизни. Так, здоровый образ жизни, ставший базовым регулятивом, включает множество компонентов: активная жизненная позиция, правильное питание, регулярные занятия спортом, сознательное отношение к здоровью, правильная организация пространства и тайм-менеджмент, экоактивизм и многое другое.

Публичное обсуждение модных тем в рамках сетевого общения позволяет блогерам создать положительный имидж посредством вербальной самоидентификации как приверженца здорового образа жизни, разделяющего ценности современной массовой культуры. Агенты сетевого общения демонстрируют знания по актуальным темам для подтверждения следования тенденциям. Эксплицитная речевая самоидентификация представителей массовой культуры в большинстве случаев сопровождается указанием на безусловный характер данного параметpa, имплицитная индикация ведения правильного, здорового образа жизни чаще воспринимается адресатом через распознавание значения употребляемых в речи транслингвальных лексических единиц, принадлежащих к тематическим полям «мода», «спорт», «правильное питание», «путешествия». Так, блогер, публикуя видеообзор о требованиях, предъявляемых к спортивной обуви, в действительности не всегда является профессиональным спортсменом, чаще демонстрация знаний в области специализированной спортивной обуви - это элемент имиджа сто- ронника модного образа жизни, в современной массовой сетевой культуре они называются лидерами мнений.

Употребление трансъязычных названий специализированной спортивной обуви обусловлено доступностью и широкой популярностью ее моделей от иностранных производителей среди российских потребителей и отсутствием в русском языке номинирующих их лексических единиц, которые отражали бы весь комплекс неотъемлемых характеристик товара и его предназначение для конкретного вида спорта / спортивной дисциплины.

Наиболее часто встречаются транслингвальные номинации спортивной обуви для бега: трейнеры (от англ. trainer) предназначены для длительных тренировок; трейловые кроссовки, очевидно от трейлраннинг (англ. trailrunning), предназначены для занятий бегом по природному рельефу в свободном темпе или в рамках соревнования; минимусы (от лат. minimus - транслингвальная единица, используемая во всех языках, но свою популярность в русском языке приобрела через английский вариант американского бренда «New Balance Minimus») - минималистичные кроссовки, имитирующие бег босиком.

Активная жизненная позиция как элемент модного образа жизни блогера требует демонстрации знаний в области туризма и путешествий. Упоминания просто «удобной обуви» уже недостаточно для привлечения и поддержания интереса подписчиков. Стремление выделиться, быть не как все, предложить читателям информацию большего объема по сравнению с другими членами цифрового сообщества заставляет авторов модных блогов употреблять транслингвальные названия специальной обуви: треккинговые ботинки (англ. trek (verb) - to go on a long and difficult journey on foot (MMD) путешествовать, гулять, особенно длительно, пешком):

(15) ...Самый важный элемент экипировки в походах и путешествиях. Высокое голенище и плотная стелька надежно фиксируют стопу и помогают преодолеть пешком даже самые большие расстояния... Если вы примерите треккинговые ботинки на ровной поверхности, например, на полу или асфальте, то они могут показаться вам слишком жесткими (XV). 


\section{МАТЕРИАЛЫ И СООБЩЕНИЯ}

Массовая культура цифровой коммуникации популяризирует транслингвальные единицы и явления, которые за ними стоят, например занятие хакингом (hiking - the activity of walking for long distances in the countryside. Someone who does this is called a hiker (MMD) - туризм - пешие прогулки на природе на большие расстояния. Человек, который этим занимается - турист):

(16) Наибольшее число любителей природы предпочитают хайкинг. Хайкеры предпочитают высокую скорость движения с малым грузом за плечами. Обувь для хайкинга отличается малым весом, эффективной вентиляцией и посадкой с плотной фиксацией голеностопа... (XVI).

Путешествия, как наземные, так и морские, являются неотъемлемой составляющей модного образа жизни, они сопровождаются облачением туриста в специальную обувь для морских вояжей, которая получает транслингвальную номинацию:

(17) Топсайдеры - были задуманы как обувь для моряков и яхтсменов, но уже давно не влекуг за собой покупку яхты - по крайней мере, не настаивают на ее наличии. Единственное, чем действительно нужно обладать, чтобы носить топсайдеры, так это готовность пренебречь носками - с палубной обувью их носить категорически не рекомендуется (XVII).

Саморепрезентация личности блогера, происходящая в рамках освещения популярных и модных тем, предполагает «правильное», то есть одобряемое обществом, современное и при этом оригинальное и индивидуальное решение проблем экологии: обувь, изготавливаемая популярными брендами из биоразлагаемых материалов или продуктов вторичной переработки, представляется как актуальная тенденция 2020-х гг.:

(18) ...Они изготовили кроссовки Alphaedge4D, используя текстиль, созданный из переработанного океанического мусора (XVIII).

Модный блогер позиционирует себя как приверженец экологического мышления - человек, руководствующийся новыми морально-этическими принципами, стремящийся к отказу от использования сырья животного происхождения для сохранения биоразнообразия планеты:

(19) Предпринимательницы хотят создать «новую роскошь» - экологичную и произведенную без жестокости по отношению к животным. Тейлор и Томас отмечают, что хотя люксовый сегмент стремится к устойчивому развитию, найти экообувь можно разве что у Стеллы Маккартни (XIX).

Указанная идея передается с помощью транслингвального префиксоида есо- / эко-. Убежденные экоактивисты проецируют концепцию вегетарианства - отказа от потребления продуктов животного происхождения - на выбор материалов, из которых изготовлена обувь:

(20) Помимо шлепанцев, в ассортименте бренда найдутся кроссовки с голенищем ковбойских сапог, спортивные сандалии со шнурками и ботинки с пришитыми бахилами. Наглядный пример того, что экологичные и на 100 \% веганские вещи могут быть ультрамодными (XIX).

Модный образ жизни подчеркивается агентами сетевого общения с помощью демонстрации принадлежности к определенным социальным группам и выбора аристократичных видов спорта, и как следствие - употребление ими в данных контекстах трансъязычной обувной лексики:

(21) Гольф-обувь - специальная обувь. И здесь мы находим элементы, уникальные именно для этой области. Например, для того чтобы облегчить игроку принятие правильной стойки для удара («коленки внутрь»), пятка Etonic-овских ботинок с внешней стороны скошена на 6 градусов, благодаря чему положение ноги во время удара будет более правильным (VII).

Наблюдаемый в примерах прием графической и грамматической адаптации заимствованных названий обуви представляет собой грамматический блендинг.

Немаловажным параметром модного образа жизни коммуниканты в цифровом пространстве считают комфорт и удовольствие, на которые также ссылаются через многочисленные транслингвальные номинации моделей спортивной обуви и таким образом реализуют интенцию о привлечении еще большего количества лиц, заинтересованных в ведении здорового образа жизни и поддержании привлекательной внешности:

(22) Покупая трейловые кроссовки, помните, что самое главное условие - удобство... Второй важнейший момент - правильно подобранный размер. 
Не стоит покупать трейловые кроссовки впритык... (XX).

Модной тенденцией жизни считается в русской блогосфере стремление к порядку и эргономичной организации пространства. Движение Fly Lady (дословно: «реактивные хозяйки» ), уже не первый год удерживающее позиции лидера среди наставников домохозяек, обучает всех желающих хитростям ведения быта с удовольствием. Семантика глагола $f l y$ («when something such as a bird, insect, or aircraft flies, it moves through the air» (COED) - когда что-то, например птица, насекомое или самолет, летит, оно движется по воздуху) изначально заложена в концепции движения Fly Lady парящие леди-«пчелки», легко и быстро выполняющие работу по дому. Метафорический перенос исходного значения fly наблюдаем в номинации флай-обувь «летательная обувь»: одна из первых рекомендаций блога - обуться в удобную пару обуви на шнуровке. Флаюшки (диминутивное обращение к домохозяйкам, практикующим данный подход) верят, что работа по дому требует собранности и организованности, что невозможно продемонстрировать в домашних плюшевых тапочках или босиком. Для этого флай-обувь (лучше кеды на белой подошве) шнуруют так, чтобы их невозможно было снять в любой момент и позволить себе прервать «полет».

\section{Заключение}

Лингвопрагматика англоязычных заимствований в русскоязычном дискурсе массовой коммуникации выражается в спонтанном подборе русскоязычным агентом и включением в свой тезаурус англоязычных номинаций, необходимых для выражения мнения при обсуждении ценностей и символов массовой культуры.

Актуальной в сетевой массовой коммуникации является дискуссия о модном образе жизни, которую лидеры мнений, или агенты сетевой коммуникации, инициируют по следующим темам: активная жизненная позиция, правильное питание, регулярные занятия спортом, сознательное отношение к здоровью, правильная организация пространства и таймменеджмент, экоактивизм и др. При раскры- тии указанных ценностей массовой культуры агенты активно включают в свою речь транслингвальные номинации обуви, которые символизируют модный образ жизни, тем самым расширяя тезаурус участников сетевой коммуникации. Проведенный анализ прагмалингвистических особенностей текстового контента о модном образе жизни позволил выявить приемы транслингвальной адаптации англоязычных названий обуви к фонографическим, грамматическим и лексическим нормам русского языка: транслитерация с элементами оглушения финального консонанта, редукция гласных в первом предударном слоге, транслингвальная деривация, частичная грамматическая категоризация и блендинг, конверсия. Перспективы исследования видятся в тематической систематизации транслингвальной адаптации англоязычных единиц в тезаурусе трансъязычной личности.

\section{СПИСОК ЛИТЕРАТУРЫ}

Горностаев С. В., 2017. Грамматическая адаптация англоязычных заимствований сферы игровой индустрии в русском языке // Известия Южного федерального университета. Филологические науки. № 1. С. 76-84. DOI: 10.18522/19950640-2017-1-76-84.

Диброва Е. И., 2008. Избранные работы по русскому языку: в 2 т. М. : ТВТ Дивизион. Т. 1.429 с. ; T. $2.470 \mathrm{c}$.

Дьяков А. И., 2003. Причины интенсивного заимствования англицизмов в современном русском языке // Язык и культура : сб. ст. Новосибирск : Новосиб. кн. изд-во. С. 35-43.

Дьяков А. И., Скворецкая Е. В., 2013. Суффикс -инг завоевывает свои позиции в русском словообразовании // Сибирский филологический журнал. № 4. С. 180-186.

Кимягарова Р. С., 1989. Типы и виды адаптаций заимствованной лексики в русском языке нового времени (XVIII-XX вв.) // Вестник Московского университета. Серия 9 , Филология. Вып. 6. С. 69-78.

Китанина Э. А., 2005. Прагматика иноязычного слова в русском языке. Ростов н/Д: РГЭУ «РИНХ». $415 \mathrm{c}$.

Князева Г. Ю., 1970. Понятие ассимиляции заимствований и методика ее исследования // Лингвистика и методика в высшей школе. М. : Изд-во МГПИИЯ им. М. Тореза. Вып. 5. C. 124-130. 
Крысин Л. П., 1968. Иноязычные слова в современном русском языке. М. : Наука. 204 с.

Крысин Л. П., 2002. Лексическое заимствование и калькирование в русском языке последних десятилетий // Вопросы языкознания. № 6 . С. 27-34.

Леонтьев А. А., 1966. Иноязычные вкрапления в русскую речь // Вопросы культуры речи. № 7. C. 60-67.

Павленко Г. В., 1998. Семантический аспект освоения англицизмов // Семантика языковых единиц. В 2 т. Т. 1 : докл. VI Междунар. конф. М. : Спорт. жизнь ; СпортАкадемПресс. C. $192-194$.

Пономарёва 3. Н., 2001. Графический образ иноязычного слова в современных русских текстах // Мир русского слова. № 1. С. 75-77.

Прокутина Е. В., 2009. Употребление нестандартной лексики англоязычного происхождения в средствах массовой информации // Вестник Челябинского государственного педагогического университета. № 8. С. 208-219.

Реформатский А. А., 1967. Введение в языковедение. М. : Просвещение. 542 с.

Свинцова С. В., 2006. Специфика структурно-семантических изменений англоамериканизмов в процессе их адаптации в испанском языке США // Вестник Саратовской государственной академии права. № 4 (49). С. 204-207.

Canagarajah S., 2002. Multilingual Writers and the Academic Community: Towards a Critical Relationship // Journal of English for Academic Purposes. № 1. P. 29-44.

Gardner-Chloros P., 2009. Code-Switching. Cambridge : Cambridge University Press. 242 p. URL: https://www.academia.edu/12864556/ Code-Switching_by_Gardner-Chloros (date of access: 23.01.2021).

Kochetova L. A., Ilyinova E. Yu., 2020. English Academic Discourse in Translinguistic Context: Corpus-Based Study of Lexical Markers // Beстник Волгоградского государственного университета. Серия 2, Языкознание. Т. 19, № 5. P. 25-37. DOI: https://doi.org/10.15688/jvolsu2. 2020.5.3.

\section{ИСТОЧНИКИ}

I - Социальная сеть «ВКонтакте». URL: https:// vk.com/wall-90443930 (дата обращения: 09.01.2021).

II - Журнал «Glamour». URL: https://www.glamour.ru/ shopping/pod-kablukom-tufli-i-sumki-iz-novyhkollekcij-christian-louboutin (дата обращения: 06.12.2020).
III - Журнал «BAZAAR». URL: https://bazaar.ru/ fashion/vybor/10-luchshikh-par-lodochek-nanizkom-kabluke/ (дата обращения: 08.09.2019).

IV - Журнал «VOGUE». URL: http://www.vogue.ru/ beauty/news/429778/ (дата обращения: 11.10.2019).

$V$ - Журнал «ELLE». URL: http:/www.elle.ru/moda/ fashion-blog/sapogi-osen-zima-2015-2016-foto/ (дата обращения: 12.09.2019).

VI - Модный словарь обуви на каблуках. URL: http:// irkfashion.ru/fashion/modn-obzor/ $\mathrm{id}=3360$ (дата обращения: 16.09.2019).

VII - Журнал «Golf Style». URL: https://issuu.com/ evgeniysvechnikov/docs/golfstylerussia (дата обращения: 02.02.2021).

VIII - Отзовик. URL: https://otzovik.com/review 423317.html (дата обращения: 03.10.2019).

$I X$ - Онлайн-магазин «Wildberries». URL: https:// www.wildberries.kg/catalog/922678/otzyvy (дата обращения: 03.10.2019).

$X$ - Новая форма сборной Уэльса 2018. URL: https:// footykits.ru/novaya-forma-sbornoj-uelsa-2018/ (дата обращения: 04.10.2019)

$X I$ - Кроссовки-внедорожники. URL: https://www. skisport.ru/articles/read/64658/ (дата обращения: 04.10.2019).

XII - Уральское таможенное управление. URL: https://utu.customs.gov.ru/news/document/ 53862 (дата обращения: 04.10.2019).

XIII - Познавательный журнал «Школа жизни». URL: https://shkolazhizni.ru/culture/articles/78252/ (дата обращения: 03.10.2019).

$X I V$ - Что такое футзалки. URL: http:/futsalki. mozello.com/stati/chto-takoe-futzalki/ (дата обращения: 03.10.2019).

$X V$ - Онлайн-магазин «Scandinavian Outdoor». URL: https://scandinavianoutdoor.ru/obuv/ trekkingovaya-obuv/ (дата обращения: 11.01.2019).

$X V I$ - Выбираем обувь: хайкинг, треккинг, альпинизм, город. URL: https://www.kant.ru/news/ 695328/ (дата обращения: 11.01.2020).

$X V I I-$ Bсе, что вам нужно знать о топсайдерах. URL: https://kiozk.ru/article/vse-cto-vam-nuzno-znato-topsajderah (дата обращения: 02.02.2021).

XVIII - Adidas Aplhaedge4D: кроссовки для защитников природы. URL: https://yandex.ru/turbo/ graziamagazine.ru/s/fashion/adidasaplhaedge4d-kroscovki-dlya-zashchitnikovprirody/ (дата обращенияz: 05.02.2021).

$X I X$-Без кожи: 7 актуальных марок веганской обуви. URL: https://www.wonderzine.com/wonderzine/ style/style/240957-eco-shoes?from=readmore (дата обращения: 12.02.2021).

$X X-10$ лучших трейловых кроссовок. URL: https:// newrunners.ru/mag/10-luchshih-trejlovyhkrossovok/ (дата обращения: 08.12.2019). 


\section{СЛОВАРИ}

COED - Collins Online English Dictionary. URL: https:// www.collinsdictionary.com (date of access: 15.09.2020).

$M M D$ - MacMillan Dictionary. URL: https://www. macmillandictionary.com/dictionary/british/ hiking (date of access: 03.01.2020).

\section{REFERENCES}

Gornostaev S.V., 2017. Grammaticheskaya adaptatsiya angloyazychnykh zaimstvovaniy sfery igrovoy industrii $\mathrm{v}$ russkom yazyke [Grammatical Adaptation of English Loanwords of Gaming Industry in the Russian Language]. Izvestiya Yuzhnogo federalnogo universiteta. Filologicheskie nauki [Proceedings of Southern Federal University. Philology], no. 1, pp. 76-84. DOI: 10.18522/1995-0640-2017-1-76-84.

Dibrova E.I., 2008. Izbrannyye raboty po russkomu yazyku: $v 2 t$. [Selected Works on Russian Language. In 2 Vols.]. Moscow, TVT Divizion, vol. 1. 429 p.; vol. 2. 470 p.

Dyakov A.I., 2003. Prichiny intensivnogo zaimstvovaniya anglitsizmov v sovremennom russkom yazyke [The Reasons for Intensive Borrowing of Anglicisms in Modern Russian]. Yazyk i ku'tura: sb. st. [Language and Culture. Collection of Articles]. Novosibirsk, Novosibirskoye knizhnoye izd-vo, pp. 35-43.

Dyakov A.I., Skvoretskaya E.V., 2013. Suffiks -ing zavoevyvaet svoi pozitsii v russkom slovoobrazovanii [The Suffix -ing Wins Its Positions in the Russian Word-Building]. Sibirskiy filologicheskiy zhurnal [Siberian Journal of Philology], no. 4, pp. 180-186.

Kimyagarova R.S., 1989. Tipy i vidy adaptatsiy zaimstvovannoy leksiki $\mathrm{v}$ russkom yazyke novogo vremeni (XVIII-XX vv.) [Borrowed Vocabulary Adaptation Types in the Russian Language of Modern Times $\left(18^{\text {th }}-\right.$ $20^{\text {th }}$ Centuries)]. Vestnik Moskovskogo universiteta. Seriya 9, Filologiya [Moscow University Philology Bulletin], iss. 6, pp. 69-78.

Kitanina Ye.A., 2005. Pragmatika inoyazychnogo slova $v$ russkom yazyke [The Pragmatics of Foreign Words in the Russian Language]. Rostov-on-Don, RGEU «RINH». 415 p.

Knyazeva G.Yu., 1970. Ponyatie assimilyatsii zaimstvovaniy i metodika yeyo issledovaniya [The Concept of Borrowings Assimilation and the Methodology of Its Study]. Lingvistika $i$ metodika $v$ vysshey shkole [Linguistics and
Methodology in Higher Education]. Moscow, Izd-vo MGPIIYa im. M. Toreza, iss. 5, pp. 124-130.

Krysin L.P., 1968. Inoyazychnye slova $v$ sovremennom russkom yazyke [Foreign Words in Modern Russian Language]. Moscow, Nauka Publ. 204 p.

Krysin L.P., 2002. Leksicheskoe zaimstvovanie i kalkirovanie $\mathrm{v}$ russkom yazyke poslednikh desyatiletiy [Lexical Borrowing and Translation Loans in the Russian Language of the Last Decades]. Voprosy yazykoznanija [Topics in the Study of Language], no. 6, pp. 27-34.

Leontyev A.A., 1966. Inoyazychnye vkrapleniya v russkuyu rech [Foreign Inclusions in Russian Speech]. Voprosy kultury rechi [Culture of Speech Issues], no. 7, pp. 60-67.

Pavlenko G.V. 1998. Semanticheskiy aspekt osvoeniya anglitsizmov [The Semantic Aspect of Anglicism Adaptation]. Semantika yazykovyh edinits. V 2 t. T. 1: dokl. VI Mezhdunar. konf. [Semantics of Linguistic Units. In 2 Vols. Vol. 1. Reports at the $6^{\text {th }}$ International Conference]. Moscow, Sportivnaya zhizn Publ., SportAkademPress Publ., pp. 192-194.

Ponomaryova Z.N., 2001. Graficheskiy obraz inoyazychnogo slova $v$ sovremennykh russkikh tekstakh [A Foreign Word Graphic Image in Modern Russian Texts]. Mir russkogo slova, no. 1 , pp. $75-77$.

Prokutina E.V., 2009. Upotreblenie nestandartnoy leksiki angloyazychnogo proiskhozhdeniya $\mathrm{v}$ sredstvakh massovoy informatsii [Use of Nonstandard Vocabulary of the English Origin in Mass Media]. Vestnik Chelyabinskogo gosudarstvennogo pedagogicheskogo universiteta, no. 8, pp. 208-219.

Reformatskiy A.A. 1967. Vvedenie v yazykovedenie [Introduction to Linguistics]. Moscow, Prosveshchenie Publ. 542 p.

Svintsova S.V. 2006. Spetsifika strukturnosemanticheskikh izmeneniy angloamerikanizmov $\mathrm{v}$ protsesse $\mathrm{ikh}$ adaptatsii $\mathrm{v}$ ispanskom yazyke SShA [Some Specific Features of the Structural and Semantic Changes of AngloAmericanisms in the Process of Their Adaptation into the US Spanish]. Vestnik Saratovskoy gosudarstvennoy akademii prava [Saratov State Law Academy Bulletin. Academy Journal], no. 4 (49), pp. 204-207.

Canagarajah S., 2002. Multilingual Writers and the Academic Community: Towards a Critical Relationship. Journal of English for Academic Purposes, no. 1, pp. 29-44.

Gardner-Chloros P., 2009. Code-Switching. Cambridge, Cambridge University Press. 242 p. URL: https:// www.academia.edu/12864556/Code-Switching by_Gardner-Chloros (accessed 23 January 2021). 
Kochetova L.A., Ilyinova E.Yu., 2020. English Academic Discourse in Translinguistic Context: CorpusBased Study of Lexical Markers. Vestnik Volgogradskogo gosudarstvennogo universiteta. Seriya 2. Yazykoznanie [Science Journal of Volgograd State University. Linguistics], vol. 19, no. 5, pp. 25-37. DOI: https://doi.org/10.15688/ jvolsu2.2020.5.3.

\section{SOURCES}

Socialnaja set "VKontakte» ["VKontakte" Social Networking Service]. URL: https://vk.com/wall90443930 (accessed 9 January 2021).

Zhurnal «Glamour» [Glamour Magazine]. URL: https:// www.glamour.ru/shopping/pod-kablukom-tuflii-sumki-iz-novyh-kollekcij-christian-louboutin (accessed 6 December 2020).

Zhurnal «BAZAAR» [BAZAAR Magazine]. URL: https://bazaar.ru/fashion/vybor/10-luchshikhpar-lodochek-na-nizkom-kabluke (accessed 8 September 2019).

Zhurnal «VOGUE» [VOGUE Magazine]. URL: http:// www.vogue.ru/beauty/news/429778 (accessed 11 October 2019).

Zhurnal «ELLE» [ELLE Magazine]. URL: http:// www.elle.ru/moda/fashion-blog/sapogi-osenzima-2015-2016-foto (accessed 12 September 2019).

Modnyj slovar obuvi na kablukah [Fashionable Dictionary of High-Heels]. URL: http:// irkfashion.ru/fashion/modn-obzor/?id=3360 (accessed 16 September 2019).

Zhurnal «Golf Style» [Golf Style Magazine]. URL: https://issuu.com/evgeniysvechnikov/docs/ golfstylerussia (accessed 2 February 2021).

Otzovik. URL: https://otzovik.com/review_423317.html (accessed 3 October 2019).

Onlayn-magazin «Wildberries» [Wildberries Online Shop]. URL: https://www.wildberries.kg/catalog/ 922678/otzyvy (accessed 3 October 2019).

Novaja forma sbornoj Ujelsa 2018 [New 2018 Welsh National Team Uniforms]. URL: https://footykits. ru/novaya-forma-sbornoj-uelsa-2018/ (accessed 4 October 2019).

Krossovki-vnedorozhniki [Off-Road Running Shoes]. URL: https://www.skisport.ru/articles/read/ 64658 (accessed 4 October 2019).
Uralskoe tamozhennoe upravlenie [The Urals Customs]. URL: https://utu.customs.gov.ru/ news/document/53862 (accessed 4 October 2019).

Poznavatelnyj zhurnal "Shkola zhizni»["Shkola zhizni” Educational Magazine]. URL: https:// shkolazhizni.ru/culture/articles/78252 (accessed 3 October 2019).

Chto takoe futzalki [What are Futsal Shoes]. URL: http://futsalki.mozello.com/stati/chto-takoefutzalki (accessed 3 October 2019).

Onlayn-magazin "Scandinavian Outdoor» [Scandinavian Outdoor Online Shop]. URL: https://scandinavianoutdoor.ru/obuv/ trekkingovaya-obuv (accessed 11 January 2019).

Vybiraem obuv: hajking, trekking, alpinizm, gorod [Choosing Shoes for Hiking, Trekking, Mountain Climbing, and the City]. URL: https:// www.kant.ru/news/695328 (accessed 11 January 2020).

Vse, chto vam nuzhno znat o topsajderah [Everything You Need to Know About Topsiders]. URL: https://kiozk.ru/article/vse-cto-vam-nuzno-znato-topsajderah (accessed 2 February 2021).

Adidas Alphaedge4D: krossovki dlja zashhitnikov prirody [Adidas Alphaedge4D: Sneakers for Environment Activists]. URL: https://yandex.ru/ turbo/graziamagazine.ru/s/fashion/adidasaplhaedge4d-kroscovki-dlya-zashchitnikovprirody (accessed 5 February 2021).

Bez kozhi: 7 aktualnyh marok veganskoj obuvi [Leatherless: 7 Popular Vegan Shoe Brands]. URL: https:/www.wonderzine.com/wonderzine/ style/style/240957-eco-shoes?from=readmore (accessed 12 February 2021).

10 luchshih trejlovyh krossovok [10 Best Trailer Running Sneakers]. URL: https://newrunners.ru/ mag/10-luchshih-trejlovyh-krossovok (accessed 8 December 2019).

\section{DICTIONARIES}

Collins Online English Dictionary. URL: https://www. collinsdictionary.com (accessed 15 September 2020).

MacMillan Dictionary. URL: https://www. macmillandictionary.com/dictionary/british/ hiking (accessed 3 January 2020). 
O.C. Волкова. Лингвопрагматика английских заимствований в русскоязычном дискурсе

\section{Information About the Author}

Olga S. Volkova, Candidate of Sciences (Philology), Associate Professor, Department of English Philology, Volgograd State University, Prosp. Universitetsky, 100, 400062 Volgograd, Russia, olgavolkova@volsu.ru, https://orcid.org/0000-0002-2163-7129

\section{Информация об авторе}

Ольга Сергеевна Волкова, кандидат филологических наук, доцент кафедры английской филологии, Волгоградский государственный университет, просп. Университетский, 100, 400062 г. Волгоград, Россия, olgavolkova@volsu.ru, https://orcid.org/0000-0002-2163-7129 